\title{
MICROSTRUCTURAL EVOLUTION DURING LASER SURFACE ALLOYING OF DUCTILE CAST IRON WITH TITANIUM
}

\begin{abstract}
Diode laser surface alloying process was used to the in-situ synthesis of TiC-reinforced composite surface layers on the ductile cast iron substrate. The obtained composite surface layers were investigated using optical and scanning electron microscopy, and XRD diffraction.

It was found that the morphology and fraction of TiC phase is directly dependent upon both the concentration of titanium in the molten pool and also the solidification rate. With increasing titanium content, the fraction of TiC increases, whereas the fraction of cementite decreases. The TiC phase promotes a heterogeneous nucleation of primary austenite grains, what reduces a tendency of cracking in the alloyed layers.

Keywords: in-situ composite, TiC, laser surface alloying, diode laser, ductile cast iron
\end{abstract}

\section{Introduction}

In the last decade much emphasis has been placed on the enhancement of surface properties of the cast iron, such as its wear and corrosion resistance [1-3]. The most of reported works have been focused on laser surface modification methods of the cast iron, mainly laser surface melting (LSM) and alloying (LSA) processes [4-6]. Both of these processes are characterized by rapid solidification and cooling rates leading to a formation of non-equilibrium phases [7-10]. As a result, developed surface layers have novel microstructures and physical properties superior to relative to the as-cast condition [11]. Additional advantage of the LSA process is the ability to change and accurate control of chemical composition of modified surface layers [12,13]. A high carbon content in the cast irons gives possibility to in-situ fabricate ceramic-reinforced composite surface layers (CRLs) via the LSA process. Because of its strong carbide forming tendency, titanium, as the alloying material for the LSA process of the cast irons, provides a unique possibility to the in-situ synthesis of TiC-reinforced CRLs [14]. On the other hand, it is well known that the ceramic-reinforced composite materials have an excellent wear resistance [15-18]. Thus, the above-mentioned surface alloying process is a very promising approach to improve the wear resistance of machine parts made of the cast irons. Unfortunately, there is very little literature available concerning such laser surface modification of the cast irons. A comprehensive analysis of microstructure evolution during this process would allow to tailor properties of working surface of machine parts made of the cast irons.
The paper presents the application of high power direct diode laser, with a rectangular laser beam spot and the top-hat beam profile, for the fabrication of TiC-reinforced surface alloyed layers (TRLs) on the ductile cast iron (DCI). Emphasis was placed on identification of the effect of processing parameters on the compositional homogeneity, microstructure and microhardness of the developed composite surface layers.

\section{Experimental}

In the present experiments, a pearlitic/ferritic DCI (ENGJS-700-2) was used as the substrate material (SM). Table 1 shows the chemical composition of the used DCI. Specimens of the SM, in the form of discs $50 \mathrm{~mm}$ in diameter and $10 \mathrm{~mm}$ thick, were ground to a surface finish of $0.5 \mu \mathrm{m} \mathrm{R}_{\mathrm{a}}$ and cleaned with acetone prior to the LSA process. Commercially pure titanium powder of average particle size of $\sim 55 \mu \mathrm{m}$ was used as the alloying material.

TABLE 1

Chemical composition of the DCI used (EN-GJS-700-2)

\begin{tabular}{|c|c|c|c|c|c|c|c|c|c|c|c|}
\hline \hline \multicolumn{10}{|c|}{ Content wt.\% } \\
\hline C & Mn & Si & Cu & Cr & Ti & Al & Ni & Mg & S & P & Fe \\
\hline 3.56 & 0.25 & 2.51 & 0.79 & 0.02 & 0.02 & 0.01 & 0.04 & 0.02 & 0.008 & 0.016 & bal. \\
\hline
\end{tabular}

A $2 \mathrm{~kW}$ continuous wave high power direct diode laser (Rofin-Sinar DL020) was adopted for single-pass and multi-pass

\footnotetext{
SILESIAN UNIVERSITY OF TECHNOLOGY, FACULTY OF MECHANICAL ENGINEERING, WELDING DEPARTMENT, 18 A KONARSKIEGO STR., 44-100 GLIWICE, POLAND

Corresponding author: damian.janicki@polsl.p
} 


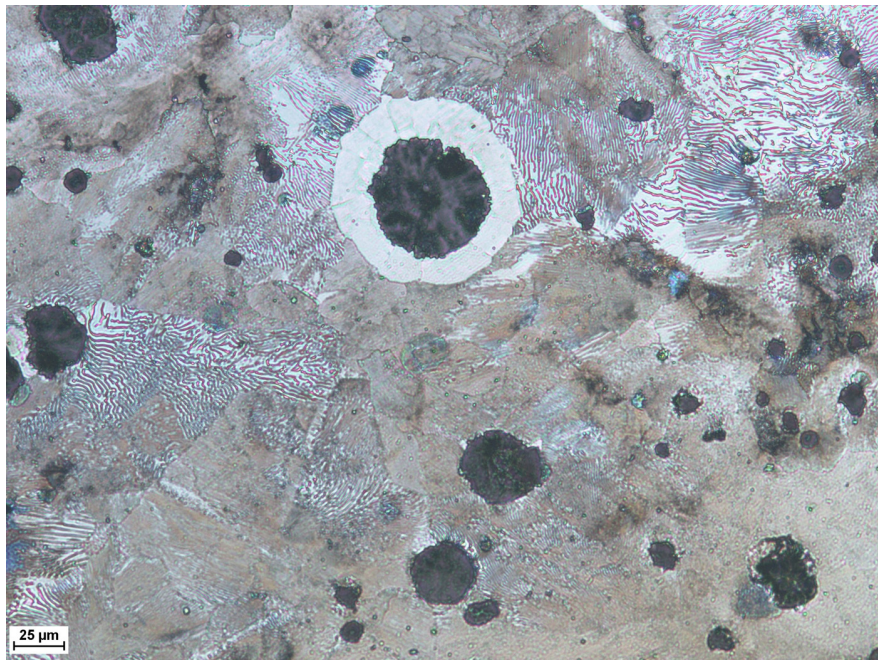

Fig. 1. Microstructure of the used DCI (EN-GJS-700-2 grade)

overlapping alloying trials. The rectangular laser beam spot of size $1.8 \times 6.8 \mathrm{~mm}$, at focal length $82 \mathrm{~mm}$, was positioned on the top surface of the SM. The short axis of the beam was set parallel to the traverse direction. The LSA process was conducted using a direct injection of alloying powder into the molten pool via an off-axis flat powder injection nozzle. To ensure a uniform powder distribution on the surface of the molten pool the nozzle shape has been fitted to the laser spot, as presented in Fig. 2. The used powder delivery system provided a feed rate accuracy of $\pm 0.5 \%$. The molten pool was protected by shielding gas - argon at a flow rate of $10 \mathrm{l} / \mathrm{min}$. The cylindrical shielding gas nozzle having a diameter of $20 \mathrm{~mm}$ was set coaxially with the powder injection nozzle.
In an effort to study the range of possible alloying parameters, a series of single-pass alloyed beads (SABs) have been made at laser power levels of $800 \mathrm{~W}, 1000 \mathrm{~W}$ and $1200 \mathrm{~W}$ with traverse speeds ranging from $1.67 \mathrm{~mm} / \mathrm{s}$ to $4.16 \mathrm{~mm} / \mathrm{s}$. The powder feed rate, defined as the amount of titanium powder provided per unit length of the $\mathrm{SAB}$, was in the range of 1.5 to $8.5 \mathrm{mg} / \mathrm{mm}$. In the first stage of the experiment the maximum powder feed rate for a given heat input level (defined by the ratio of the laser power and the traverse speed) has been establish, Fig. 3. The maximum powder feed rate was determined as the feed rate at which uniform distribution of titanium throughout the fusion zone was occurred and no partially melted powder particles were observed. The second stage of the experiment was focused on determining the effect of processing parameters on the morphology and volume fraction of TiC phase, and microstructural evolution of the TRLs in general. The TRLs were fabricated via multi-pass overlapping alloying process under optimal processing conditions, Table 2. Additionally, to provide a deeper analysis of microstructural changes during the investigated surface alloying process, the surface melted layer (SML) were also produced on the used DCI under selected conditions,

The macrostructure of the SABs was determined by optical microscopy and image analyzer software. Microstructural investigations were carried out using both optical and scanning electron microscope (SEM) equipped with an energy dispersive X-ray spectrometer (EDS). X-ray diffraction (XRD) analysis of both TRLs and SML was conducted using a PANalytical X'Pert PRO MPD X-ray diffractometer equipped with an X'Celerator detector and a Co- $\mathrm{K}_{\alpha}(\lambda=1.79 \AA)$ source. The X-ray tube was operated at $40 \mathrm{kV}$ and $30 \mathrm{~mA}$. The fraction of phases in the TRLs

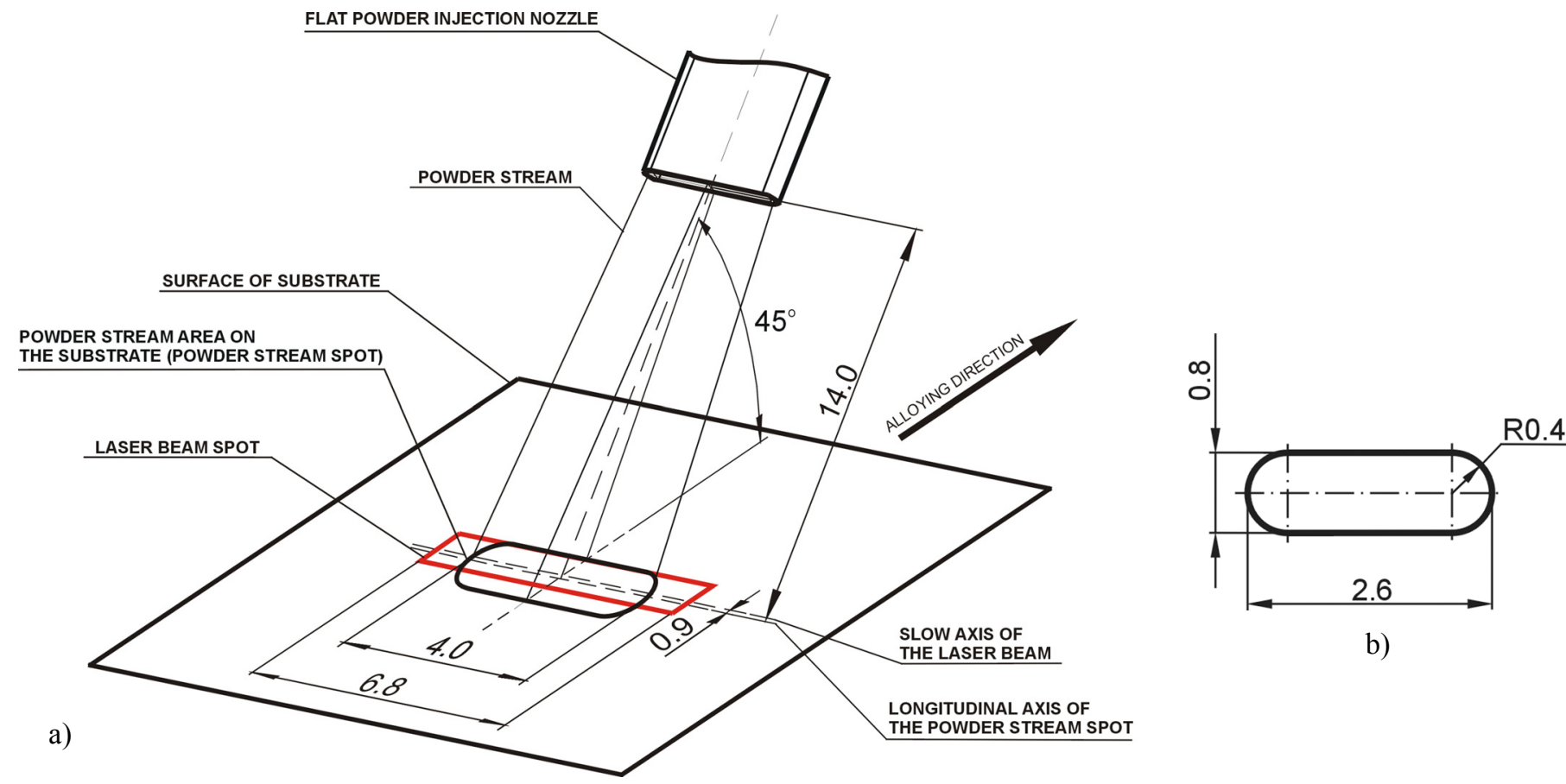

Fig. 2. Schematic illustration showing the alignment of the flat powder injection nozzle relative to the laser beam spot (a) and the geometry of the flat nozzle opening (b) 
Influence of process parameters on the Ti content and TiC fraction in the TRLs (in the optimal range of processing parameters)

\begin{tabular}{|c|c|c|c|c|c|c|}
\hline $\begin{array}{c}\text { Processing } \\
\text { condition no.* }\end{array}$ & $\begin{array}{l}\text { Laser power } \\
(\mathrm{W})\end{array}$ & $\begin{array}{c}\text { Traverse speed } \\
(\mathrm{mm} / \mathrm{s})\end{array}$ & $\begin{array}{c}\text { Heat input** } \\
(\mathrm{J} / \mathrm{mm})\end{array}$ & $\begin{array}{c}\text { Powder feed rate } \\
(\mathrm{mg} / \mathrm{mm})\end{array}$ & $\begin{array}{l}\text { Total Ti content in the TRL } \\
\text { (wt.\%) }\end{array}$ & $\begin{array}{c}\text { Fraction of TiC in the TRL } \\
\text { (vol.\%) }\end{array}$ \\
\hline $\mathrm{T} 1$ & 1200 & 1.66 & 720 & 7.5 & $8.1 \pm 0.80$ & $13.9 \pm 1.4$ \\
\hline $\mathrm{T} 2$ & 1200 & 3.33 & 360 & 1.5 & $3.8 \pm 0.33$ & $6.6 \pm 0.6$ \\
\hline T3 & 1200 & 3.33 & 360 & 3.0 & $5.9 \pm 0.54$ & $9.7 \pm 0.9$ \\
\hline $\mathrm{T} 4$ & 1200 & 3.33 & 360 & 4.0 & $6.8 \pm 0.66$ & $11.4 \pm 1.1$ \\
\hline $\mathrm{T} 5$ & 1200 & 4.16 & 288 & 4.0 & $6.7 \pm 0.71$ & $11.6 \pm 1.5$ \\
\hline T6 & 1200 & 2.50 & 480 & 4.5 & $7.2 \pm 0.77$ & $12.2 \pm 1.0$ \\
\hline M1 & 1200 & 1.66 & 720 & - & - & - \\
\hline
\end{tabular}

Remarks: *T and M stand for the TRL and SML fabricated at an overlap ratio of $50 \%$, respectively; ** defined as the laser power divided by the traverse speed.

and SML was evaluated by the Rietveld refinement method using the FullProf software package. Additionally, the amount of $\mathrm{TiC}$ and cementite were calculated from micrographs by mean of the Carl Zeiss digital image processing software.

Microhardness profiles on traverse section of TRLs were measured using Wilson Wolpert 401 MVD Vickers hardness tester with a $200 \mathrm{~g}$ load for a dwell time of $10 \mathrm{~s}$.

\section{Results and discussion}

The results indicated a general trend towards increasing the maximum titanium powder feed rate (MFR), providing the uniformly alloyed SAB, with increasing heat input (HI) level. Fig. 3 presents the relationship between the HI and the MFR. However, it should be noted that the increase in $\mathrm{HI}$ leads simultaneously to the higher fusion area of the SAB. As the result, the maximum Ti content in the SAB, was in the range of 5.0-6.0 wt.\%. The increase of the powder feed rate above the upper limit (marked by dashed line on Fig. 3), at given HI level, results in an agglomeration of $\mathrm{TiC}$ particles at the $\mathrm{SAB}$ centre, leading to the formation of voids and micro cracks, Fig. 4.

The limitation of the titanium powder feed rate is considered to be related to the character and the intensity of the fluid flow in the molten pool. It is known that the pattern of the fluid flow in the molten pool, which is introduced and controlled by the surface tension gradient, determines both fusion zone shape and uniformity of its composition [19]. The cross-sectional macrograph of the SAB, presented in Fig. 5a, indicates that, during the investigated LSA process, the surface tension temperature coefficient on the molten pool surface was positive. In such a case, the surface tension is highest at the center of the molten pool and produces fluid flow inward along the surface of the molten pool [20]. As a result, the SABs have hemispherical shape in cross section. Furthermore, the increase in the laser power, at given traverse speed, leading to higher fluid flow velocity in the molten pool driven by the surface tension gradient, results in concave bead profile and deeper fusion at the center. The above proposed mechanism of heat and mass transfer in the molten pool has been confirmed by EDS line-scan analysis collected on the cross-section of the SAB produced at the alloying

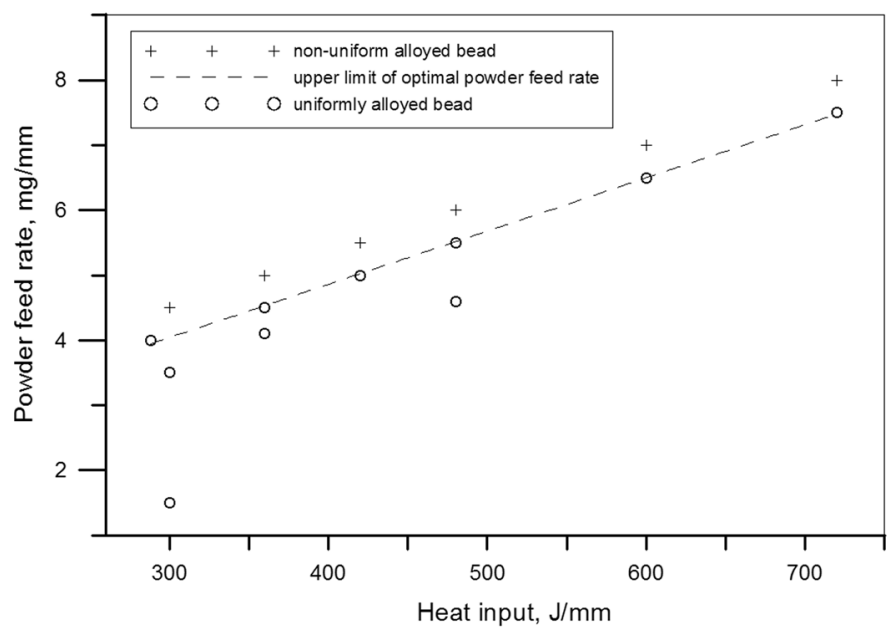

Fig. 3. Effect of the HI level on the upper limit of powder feed rate providing the uniformly alloyed $\mathrm{SAB}$

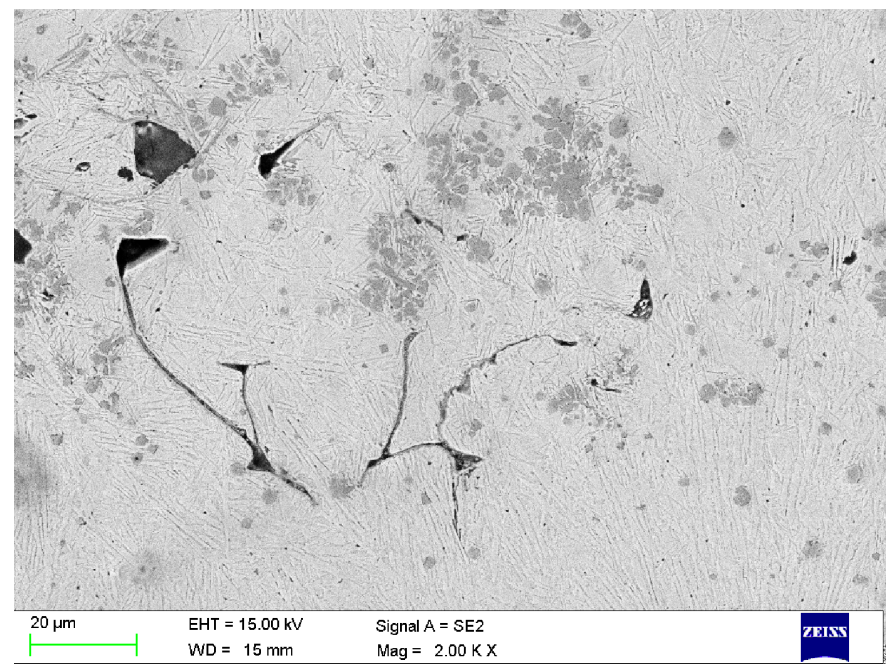

Fig. 4. SEM micrograph showing defects in the SAB produced at the $\mathrm{HI}$ of $360 \mathrm{~J} / \mathrm{mm}$ and powder feed rate of $5.0 \mathrm{mg} / \mathrm{mm}$

conditions no. T6 (Table 2), Fig. 6. A composition profile taken at mid depth of that SAB along line parallel to the bead surface revealed Ti enrichment in the center of the bead, whereas the depth profile shown homogeneous distribution of Ti. The above observations are in good agreement with the metallographic 
characterisation, which confirmed the highest volume fraction of $\mathrm{TiC}$ phase in the central area of each SAB. However, a multi-pass overlapping alloying process at $50 \%$ overlap ratio significantly improves uniformity of TiC distribution throughout the TRLs, Fig. 7. Additionally, those TRLs exhibited the uniform thickness and also relatively flat and smooth top surface, Fig. 5b. In the optimal range of alloying conditions, typical dimensions of the $\mathrm{SAB}$ were width of approx. $5.5 \mathrm{~mm}$ and depth of fusion in the range of 0.7 to $1.4 \mathrm{~mm}$. In turn, the TRL thickness was limited to approx. $1.3 \mathrm{~mm}$.

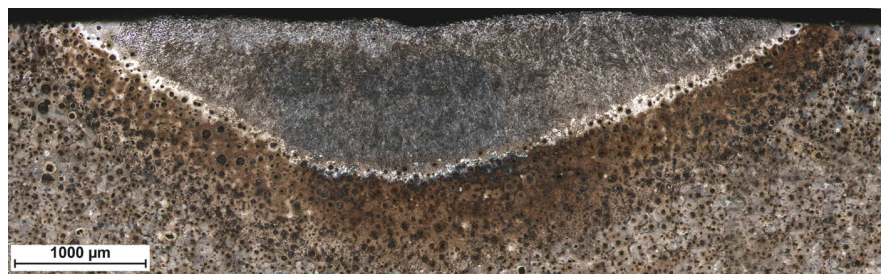

a)

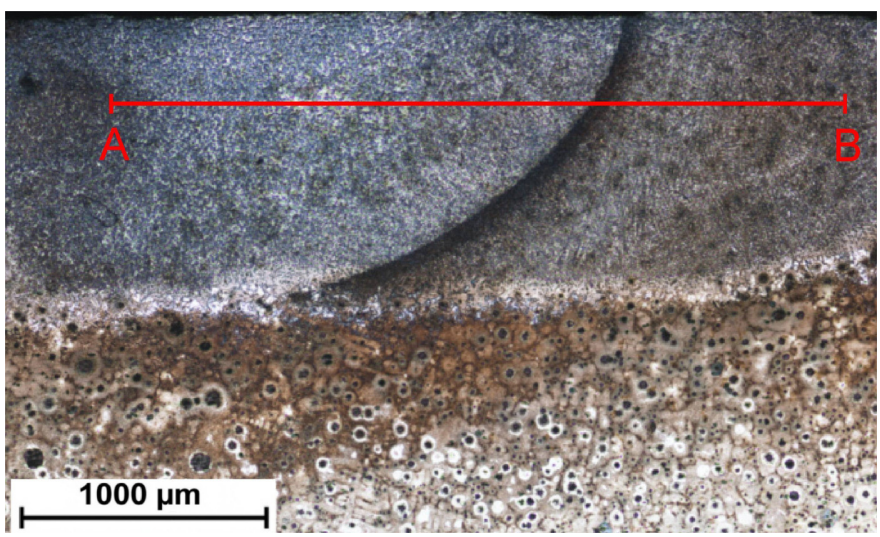

b)

Fig. 5. Macrographs of the SAB (a) and TRL (b) produced under processing parameters no. T6 (Table 2)
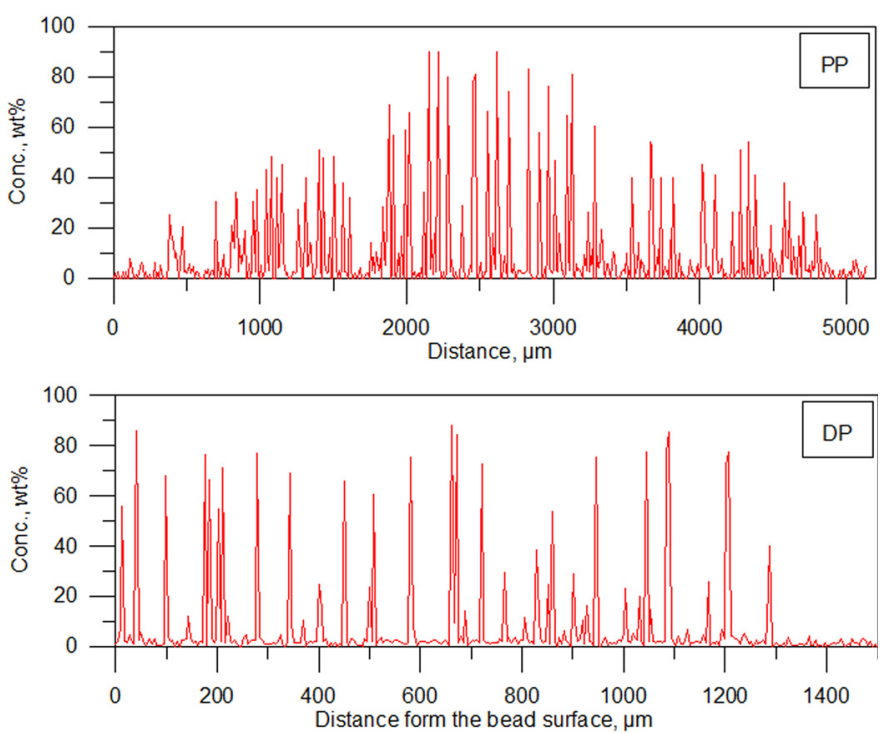

Fig. 6. Titanium concentration profiles on the cross-section of SAB produced under conditions no. T6 (Table 2). Results from SEM/EDS line-scans analysis: PP - profile taken along line parallel to the bead surfaces at $300 \mu \mathrm{m}$ depth, DP - depth profile in the center of the bead

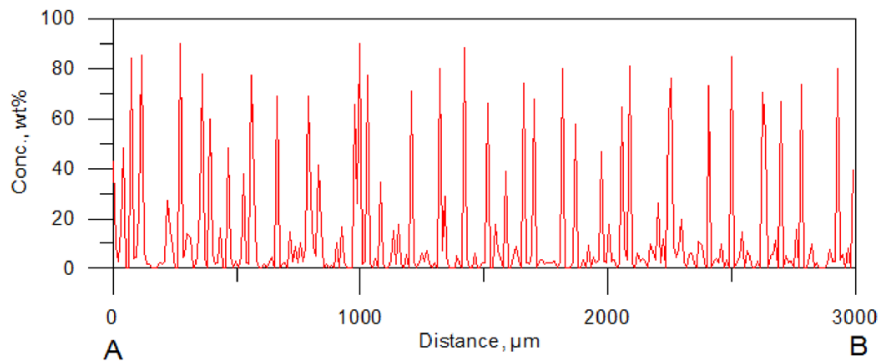

Fig. 7. Titanium concentration profile on the cross-section of TRL produced using overlap ratio of $50 \%$ and processing parameters no. T6 (TablE 2); profile taken along the line marked in Fig. 5b

Fig. 8 shows low magnification cross-sectional optical micrographs of the SABs produced at the heat input of $360 \mathrm{~J} / \mathrm{mm}$ and different powder feed rate of $1.5 \mathrm{mg} / \mathrm{mm}$ and $4.0 \mathrm{mg} / \mathrm{mm}$ (processing condition no. T2 and T4, respectively, Table 2). Generally, the microstructure of the TRLs consists of TiC particles, primary austenite dendrites partially transformed to martensite and the ledeburite structure in the interdendritic regions, Fig. 9. The TiC particles were observed in both the primary austenite dendrites and interdendritic regions. As can be seen in Fig. 8, the morphology of austenite grains varies with changes in the Ti content. At low Ti content (no. T2, Table 2) the SAB showed the formation of very fine columnar dendritic grains. In this case, the primary growth direction of the dendrites is generally perpendicular to the fusion boundary and towards the bead face there is a systematic change in the dendrite growth direction. Additionally, at the bead center, directly below the bead surface, the equiaxed growth occurs, due to a low thermal gradient and a large undercooling. It should be noted that an increase of the Ti concentration in the molten pool significantly reduced the extent of columnar dendritic region. The SAB produced under processing conditions no. T4 (Table 2) exhibits almost completely equiaxed growth in the bead center, Fig. 8b. The above change in the morphology of primary austenite grains can be attributed to the combined effect of two aspects of the TiC phase formation. Firstly, TiC particles promote a heterogeneous nucleation of primary austenite grains. Because of significantly higher thermal stability in comparison to the primary austenite, the $\mathrm{TiC}$ is the first phase which precipitates from the liquid in the molten pool. The resultant $\mathrm{TiC}$ particles act as nucleating agents for the primary austenite grains formation. The higher Ti concentration in the molten pool, the higher number of austenite nuclei, what in turn promotes the equiaxed growth of the austenite. Moreover, the reorientation of the columnar dendritic grains in the bead no. T2 (Fig. 8a) can also be the result of the heterogeneous nucleation. It is important to remark that the equiaxed growth of austenite dendrites allows to produce crack-free SABs and also significantly limits the TRLs' tendency for cracking. In contrast, the single-pass surface melted beads, produces at the same HI level, are highly prone to formation of centreline cracks [11]. The second aspect is a fact that the in-situ synthesized $\mathrm{TiC}$ particles are the result of an exothermic reaction between 


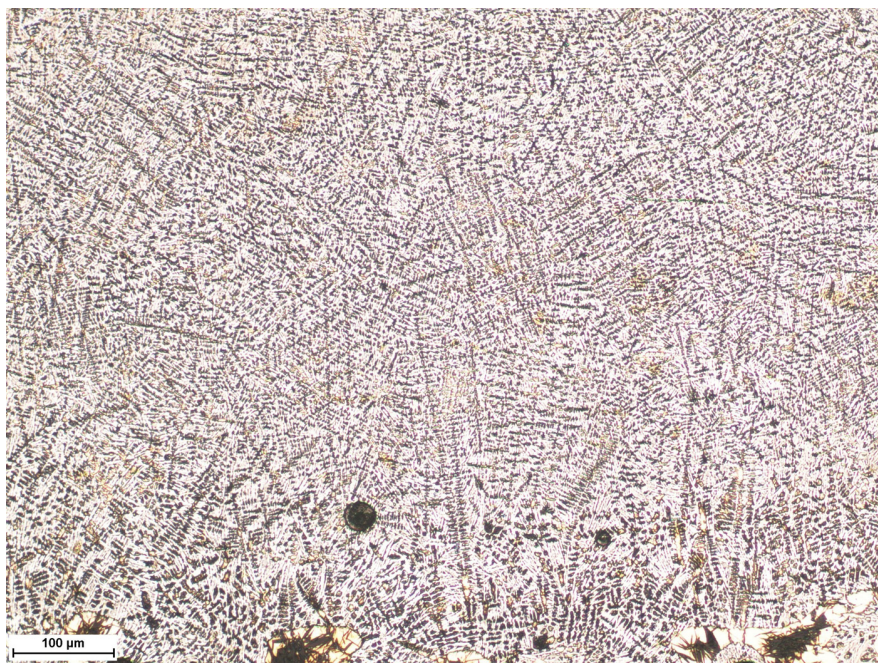

a)

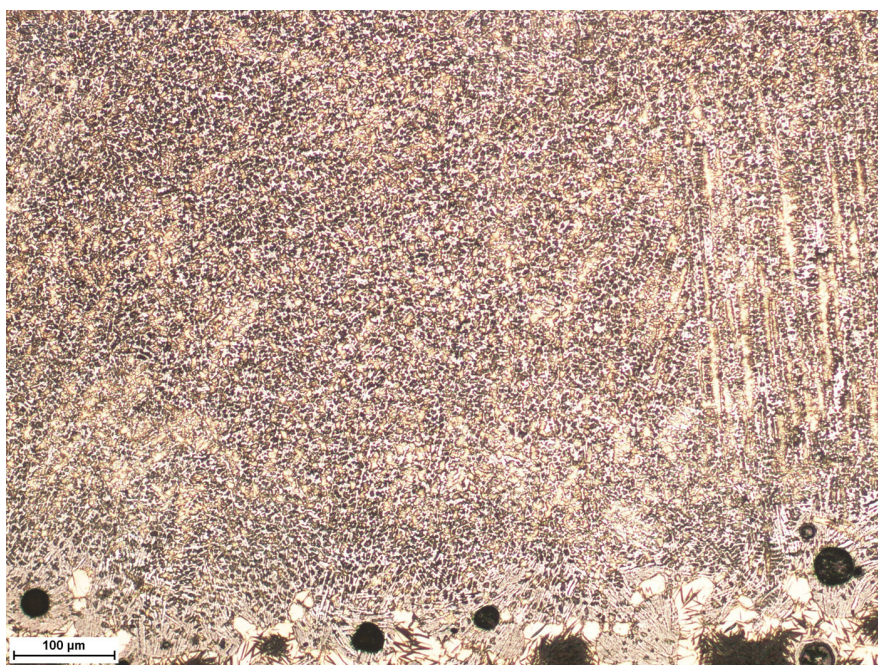

b)

Fig. 8. Optical micrographs of the SABs produced under processing conditions: a) T2; b) T4, Table 2

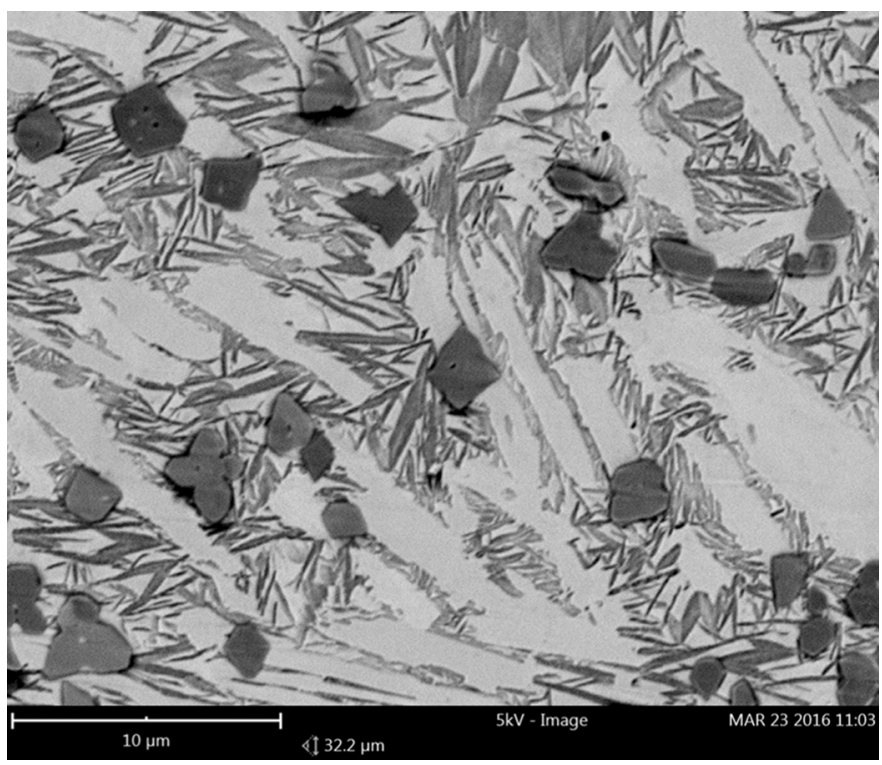

Fig. 9. Typical SEM micrograph taken from the mid-section of the TRL produced under processing conditions no. T3, Table 2 liquid titanium and carbon in the molten pool during alloying process. Consequently, the higher fraction of $\mathrm{TiC}$ particles, associated with higher Ti content, indicates larger amount of heat generated directly in the molten pool, reducing thermal gradients and cooling rates in the molten pool.

Metallographic examinations of the TRLs indicated a general trend towards increasing volume fraction of TiC phase with increasing the powder feed rate, that is, with increasing Ti concentration in the molten pool. When comparing the microstructure of TRLs with different Ti contents (comparing TRLs produced under condition no. T2 and T4, Table 2) a direct impact of $\mathrm{Ti}$ concentration in the molten pool on the size and shape of TiC particles is also observed, Fig. 10. Note that, those TRLs were produced at the same laser power level and traverse speed, Table 2. The maximum Ti content in the TRLs produced using overlap ratio of 50\% was found to be approx. $8 \mathrm{wt} . \%$. At this $\mathrm{Ti}$ content, the volume fraction of $\mathrm{TiC}$ was approx. 14 vol.\%. In general, the increase in traverse speed, at constant $\mathrm{Ti}$ concentration in the molten pool and laser power level, reduces the size of TiC in the TRLs. In the case of the TRLs containing about $7 \mathrm{wt}$ \% $\%$ Ti, with increasing traverse speed from $2.50 \mathrm{~mm} / \mathrm{s}$ to $4.16 \mathrm{~mm} / \mathrm{s}$, the morphology of $\mathrm{TiC}$ changes form dendritic (up to $10 \mu \mathrm{m}$ in size) to cubic $(<5 \mu \mathrm{m}$ in size). However, at the same time, the volume fraction of TiC essentially did not change. Furthermore, in each TRL, the size of TiC particles varies from the fusion boundary to the surface of the TRL. The above variation in TiC size is associated with the change in the solidification conditions. A higher cooling and growth rates related to higher traverse speeds limit TiC coarsening. EDS microanalyses, taken from regions adjacent to the fusion boundary of the TRL produced at the highest traverse speed of $4.16 \mathrm{~mm} / \mathrm{s}$ revealed a minor content of $\mathrm{Ti}(\sim 1.0 \mathrm{wt} . \%)$ in the martensite/ austenite matrix. This suggests that these solidification conditions are too rapid to enable a complete reaction between $\mathrm{Ti}$ and $\mathrm{C}$ in the molten pool.

The XRD analysis confirmed that the Ti content directly affects volume fractions of $\mathrm{TiC}$ and cementite in the TRLs, Fig. 11. The presence of retained austenite in both TRLs and SML was also confirmed by XRD analysis. The fractions of cementite and retained austenite in the SML were approx. 63 vol. $\%$ and $17 \mathrm{wt} . \%$, respectively. In the case of TRL containing approx. $7 \mathrm{wt} . \%$ Ti (processing conditions no. T6, TABLE 2), the fractions of cementite and retained austenite were found to be approx. 32 vol. \% and $28 \mathrm{wt} . \%$, respectively. The relatively high amount of the retained austenite in both the SML and TRLs can be attributed to high cooling rates leading to the carbon supersaturation of the austenite. The literature concerning the laser treatment of the cast irons suggests that under non-equilibrium cooling conditions, the austenite becomes supersaturated in carbon, what suppresses the martensitic transformation [11,21]. It is noteworthy that the above microstructure evolution undergoes without almost any change in the fraction of martensite. XRD analysis showed that the fraction of martensite in the abovementioned SML and TRL was approx. 20 wt.\% (the average amount in each surface layer). 


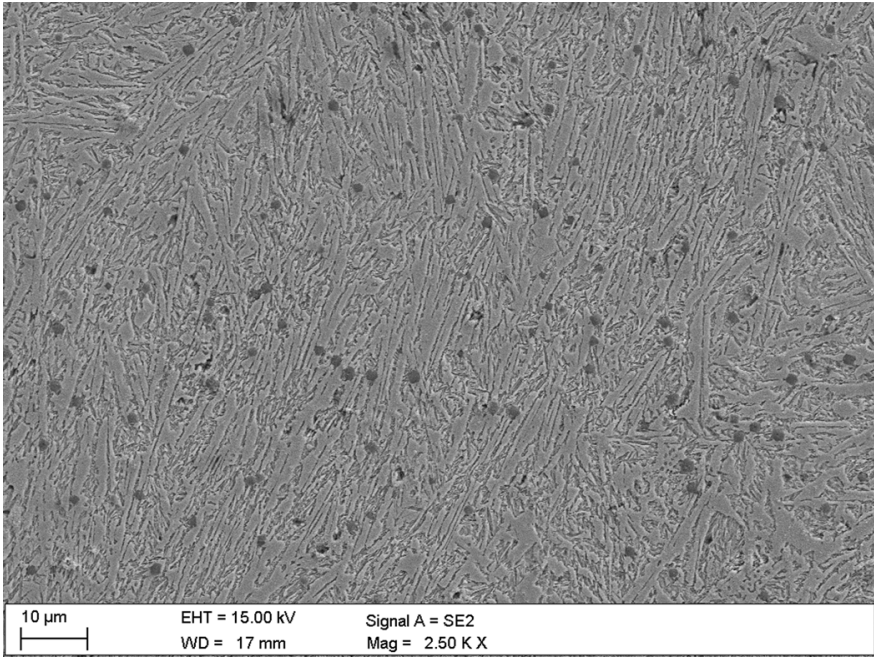

a)

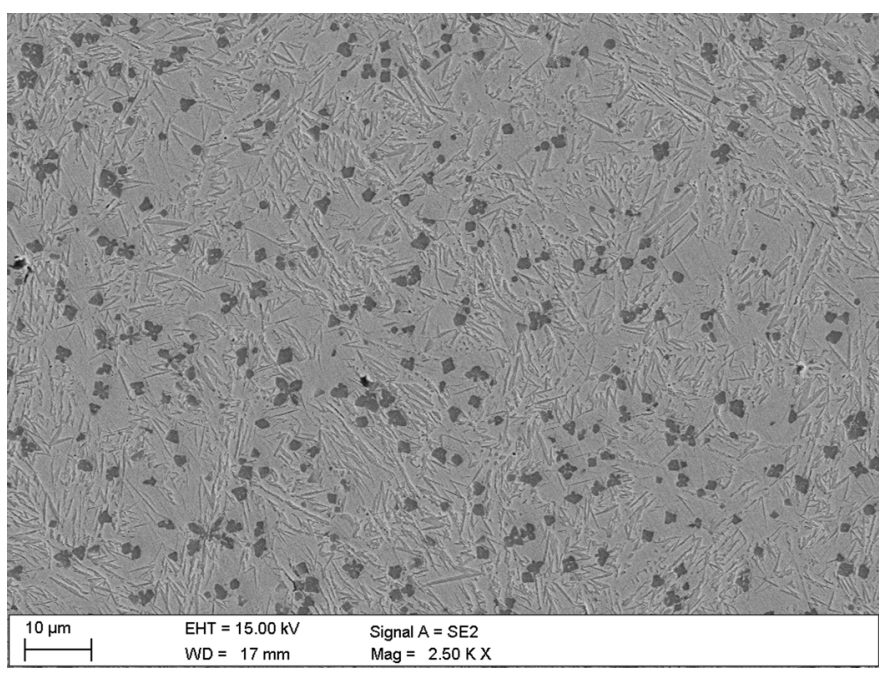

b)

Fig. 10. SEM micrographs taken from the mid-section of the TRLs produced under processing conditions no.: (a)T2; (b) T4, Table 2

The microhardness measurements of the TRLs well correlate with the above microstructural characterisation, Fig. 12. Generally, the hardness of the TRLs is directly dependent on the fraction of cementite, which in turn is connected with Ti content. The SML which contain the highest fraction of cementite has the average hardness value of $800 \mathrm{HV}$. In the case of TRLs, the average hardness decreases gradually with the increase of $\mathrm{Ti}$ content. The TRL with the highest Ti content $(\sim 8 \mathrm{wt} \%)$, that is, the highest TIC fraction has the average hardness of $650 \mathrm{HV}$.

\section{Conclusions}

The in-situ TiC-reinforced composite surface layers on the ductile cast iron substrate having the uniform distribution of TiC particles were achieved by diode laser surface alloying with a pure titanium powder. The TiC fraction in the TRLs is directly connected with the Ti concentration in the molten pool. In turn, the uniform distribution of $\mathrm{TiC}$ occurs at uniform Ti distribu-

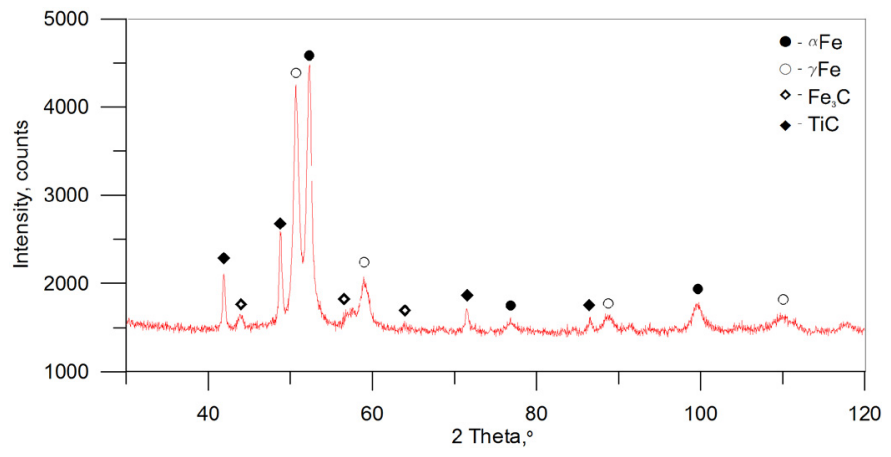

a)

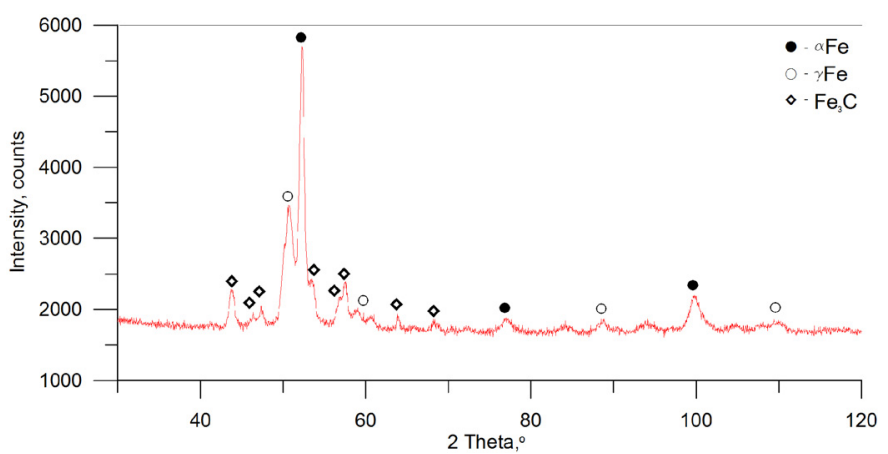

b)

Fig. 11. XRD patterns of the TRL (a) and SML (b) produced under processing conditions no. T6 and M1, respectively, Table 2

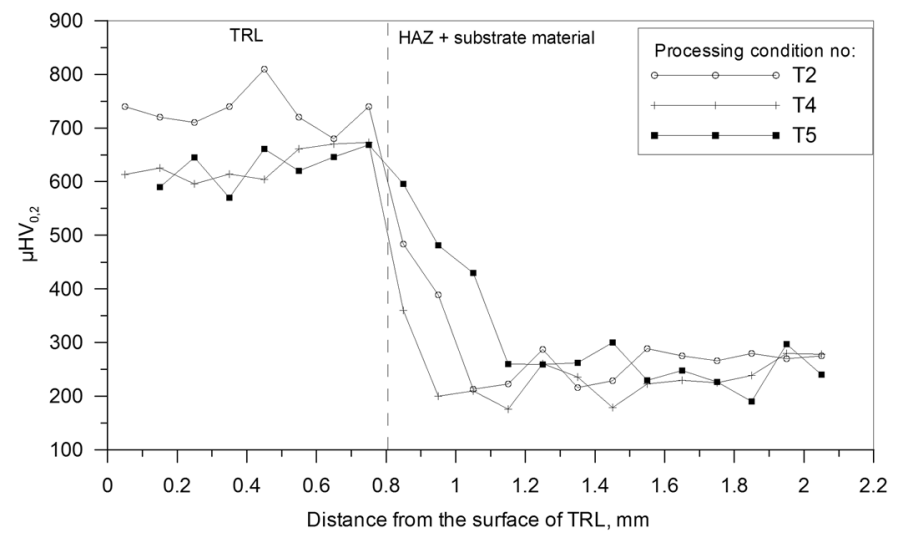

Fig. 12. Microhardness profiles on the cross section of the TRLs produced under condition no. T2, T4 and T5 with overlap ratio of $50 \%$, Table 2

tion in the molten pool. The highest Ti concentration providing uniformly alloyed TRLs was found to be approx. $8 \mathrm{wt} . \%$. The resulting TRL contained 13.9 vol.\% TiC. The limitation of Ti concentration in the molten pool is associated with the intensity and pattern of the fluid flow in the molten pool. With increasing Ti concentration in the molten pool, the volume fraction of $\mathrm{TiC}$ increases, whereas the cementite fraction decreases. Because of its high thermal stability, the $\mathrm{TiC}$ phase promotes a heterogeneous nucleation of primary austenite grains, what reduces a cracking tendency of the TRL. Morphology and size of TiC particles are directly dependent upon both the Ti concentration in the molten pool and also solidification rate. 


\section{Acknowledgement}

Publication of this article was funded by statutory grant of Faculty of Mechanical Engineering, Silesian University of Technology.

\section{REFERENCES}

[1] J.R. Davis. ASM Specialty Handbook, Cast Irons, 1996, ASM International.

[2] K. Janerka, M. Kondracki, J. Jezierski, J. Szajnar, M. Stawacz, J. Mater. Eng. Perform. 23, 2174-2181 (2014).

[3] A. Studnicki, R. Dojka, M. Gromczyk, M. Kondracki, Arch. Foundry Eng. 16, 117-123 (2016).

[4] B.S. Yilbas, I. Toor, C. Karatas, J. Malik, I. Ovali, Opt. Laser Eng. 64, 17-22 (2015).

[5] J.H. Abbud, Materials and Design 35, 677-684 (2012).

[6] K.F. Alabeedi, J.H. Abboud, K.Y. Bnounis, Wear 266, 925-933 (2009).

[7] M. Król, P. Snopiński, B. Tomiczek, T. Tański, W. Pakieła, W. Sitek, P. Est. Acad. Sci. 65/2, 107-116 (2016).

[8] D. Janicki, Proc. SPIE 8703, Laser Technology 2012: Applications of Lasers, 87030Q (2013).
[9] D. Janicki, M. Musztyfaga-Staszuk, Stroj. Vestn-J. Mech. E. 62 (6), 363-372 (2016).

[10] A. Lisiecki, Metals 5, 54-69 (2015).

[11] D. Janicki, Appl. Mech. Mater. 809-810, 423-428 (2015).

[12] M. Bonek, Arch. Metall. Mater. 59 (4), 1647-1651 (2014).

[13] M. Musztyfaga-Staszuk, L.A. Dobrzański, Cent. Eur. J. Phys. 12 (12), 836-842 (2014).

[14] H.I. Park, K. Nakata, S. Tomida, J. Mater. Sci. 35, 747-755 (2000).

[15] A. Klimpel, L.A. Dobrzański, A. Lisiecki, D. Janicki, J. Mater. Process. Tech. 164, 1046-1055 (2005).

[16] A. Czupryński, J. Górka, M. Adamiak, Metalurgija 55 (2), 173-176 (2016).

[17] J. Górka, T. Kik, A. Czupryński, W. Foreiter, Weld. 28 (10), 749755 (2014).

[18] S. Boncel, J. Górka, S. Milo, P. Shaffer, K. Koziol, Materials Letters 116, 53-56 (2014).

[19] J.F. Lancaster, Metallurgy of welding, 1980 Springer Netherland.

[20] C.R. Heiple, J.R. Roper, R.T. Stanger, J. Aden, Weld. J. 62, 72-77 (1983).

[21] N. Zarubova, V. Kraus, J. Cermak. J. Mater. Sci. 27, 3487-3496 (1992). 